\title{
REDUCTION OF THE WAVE OVERTOPPING DISCHARGE AT DIKES IN PRESENCE OF CROWN WALLS WITH BULLNOSES
}

\author{
Barbara Zanuttigh $^{1}$, Sara Mizar Formentin ${ }^{1}$
}

\begin{abstract}
New numerical and laboratory investigations on wave overtopping at dikes with crown walls were carried out. The main objective of the experiments, presented for the first time in this contribution, is to investigate the effects of the inclusion of bullnoses on the top of crown walls to reduce the average overtopping discharge $q$. The study extends the experience available on structures with bullnoses, which is so far limited to dikes with promenades under non-breaking wave conditions. The new data on $q$ resulting from the campaign of experiments are compared with the existing predicting formulae for $q$ of the EurOtop manual (2016), in order to verify and upgrade their range of validity. A formulation for a new correction coefficient $\gamma^{* *}$ to be included in the formulae is proposed to account for the effects of the bullnose also in case of structures subjected to breaking waves. A simple solution to represent the geometry of the bullnoses in the EurOtop Artificial Neural Network (ANN) is investigated. The solution, which avoids the ANN re-training and does not require the inclusion of new input parameters, applied to new and existing data gives promising results.
\end{abstract}

Keywords: wave overtopping discharge; experimental data; numerical modelling; bullnose; crown wall; Artificial Neural Network

\section{INTRODUCTION}

The effects of climate change with increased sea level and intensity of the extreme storms lead to an increase of the loads and of the expected overtopping at existing seawalls. The inclusion of bullnoses in the design of seawalls seems to significantly reduce the wave overtopping discharge $q$ and may be an effective solution to face climate change while limiting the increase of the seawalls height and the costs.

The experimental work by Van Doorslaer et al. (2015) is the only systematic study available so far about the effects of bullnoses on the reduction of $q$. Focusing on the typical geometry of the Belgian coastlines, and on non-breaking waves conditions exclusively, they developed a number of formulae, adopted then by EurOtop (2016), to parametrize the combined effect of wall, bullnose and berm, in case the crown wall is placed on the dike slope or at the end of a promenade.

The work we are proposing here starts from these findings, to analyze a different case: dikes with a finite horizontal crest width and an inshore crown wall, with and without a bullnose (bn, hereinafter), subjected to both breaking and non-breaking wave conditions. The aim is to verify whether the formulations developed by Van Doorslaer et al. (2015), VD hereinafter, can still be used or require some modifications to complete the existing design formulae.

New numerical and experimental modelling were performed to extend the experience collected by VD. The numerical modelling was carried out with the 2DV RANS VOF code developed by the University of Cantabria (Lara et al., 2011) and recently modified by Formentin \& Zanuttigh (2018) to reproduce a dry outflow boundary condition. The experiments were conducted in the wave flume of the Hydraulic Laboratory of the University of Bologna at the model scale of 1:20. Overall, the new experience collected includes 91 numerical and 112 experimental tests, which are presented and described in this contribution for the first time.

The overtopping discharges resulted from the new experiments are compared to the existing formulae. Separate analyses are proposed for non-breaking and breaking conditions. In the first case, the analysis aims at verifying and extending the validity of the reduction coefficient $\gamma^{*}$ proposed by VD to model the effect of the bn. As for breaking waves, different solutions have been investigated to set-up a coefficient analogous to $\gamma^{*}$ to be included in the EurOtop formulae for the prediction of $q$. The solutions are presented and discussed and a new formulation for $\gamma^{* *}$, valid for both non-breaking and breaking waves, is finally presented.

The application of the EurOtop ANN to the new and existing data with bn is then investigated. A solution to represent the geometry of the bn without introducing new input parameters is proposed and the results are shown.

The conclusion of the work are proposed at the end of the contribution.

\section{STRUCTURE SCHEMATIZATION}

All the structures investigated within the new numerical and experimental campaign are smooth dikes with a short crest width and a crown wall placed at the end of the crest. The crown wall might or

${ }^{1}$ DICAM, University of Bologna, V.le Risorgimento 2, Bologna, BO, 40136, Italy 
not include a bn, which is defined by the characteristic parameters $\lambda$, the ratio between the bn height and the wall height $h_{w}$, and $\varepsilon$, the inclination of the bn. Figure 1 shows an example cross-section of the tested configurations, where the parameters adopted to describe the geometry are based on the conventions of the EurOtop manual and database (Zanuttigh et al., 2016-a).

All the new structures are schematized as smooth berms with crown walls. The choice to adopt the berm-scheme is made to be consistent with the EurOtop representation of the (similar) tests by VD and coherent across the EurOtop database used to train the EurOtop ANN. Based on the berm-type schematization of the new tests:

- $\quad$ the dike crest width is represented as the berm width $(B)$ and its emergence with respect to the still water level is the berm emergence $\left(h_{b}<0\right)$;

- the dike slope below the berm is $\cot \left(\alpha_{d}\right)$, while the slope of the part of the structure above the berm $\cot \left(\alpha_{u}\right)$ is given by the weighted average of the wall inclination $\left(\alpha_{w}=90^{\circ}\right)$ and the bn inclination $(\varepsilon)$, i.e.:

$$
\cot \left(\alpha_{u}\right)=\frac{\lambda \cdot h_{w} \cdot \cot (-\varepsilon)+(1-\lambda) \cdot h_{w} \cdot \cot \left(\alpha_{w}\right)}{1}
$$

where $\varepsilon$ is taken with the negative sign because the bn inclination is opposite with respect to the dike inclination $\left(\alpha_{d}\right)$. Eq. (1) is necessary to calculate $\cot \left(\alpha_{u}\right)$ because the whole crown wall height $\left(R_{c}\right)$ is included in the run-up area above the still water level (i.e. $R_{c} \leq 1.5 H_{m 0, t}$, see Fig. 1 and the details of tested configurations, reported in Tables 1 and 2);

- the parameter $\cot \left(\alpha_{i n c l}\right)$, i.e. the cotangent of the mean angle which the structures make with a horizontal, including the berm, is calculated as indicated by Zanuttigh et al. (2016, a);

- $\quad$ the parameters $G_{c}$ and $A_{c}$ are set equal to 0 and to $R_{c}$, respectively. These parameters were used in EurOtop to describe the upper part of overtopped structures with crest and crown walls, but specifically in case of rubble mound breakwaters, where the water can penetrate into the crest and disappear, giving less overtopping (Van der Meer et al., 2009). In case of impermeable structures, $G_{c}=0$ and $A_{c}=R_{c}$.

- $\quad$ similarly to the validated assumptions by VD, the reduction berm $\gamma_{b}$ is assumed to be equal to 1 and the breaker parameter $\xi_{m-1,0}$ is calculated based on $\cot \left(\alpha_{d}\right)$.

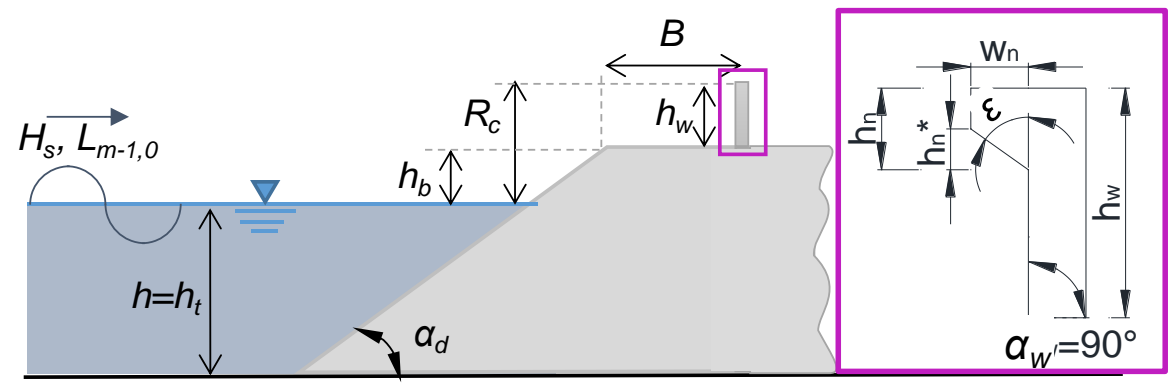

Figure 1. Scheme of a dike cross-section with crown wall and with our without bullnose, with reference to the symbols mentioned in the article.

\section{NUMERICAL AND EXPERIMENTAL INVESTIGATION}

This Section illustrates the new database of numerical and experimental tests, describing the set-up of the laboratory facility and of the numerical code, and providing the details of the tested configurations. The results of the validation of the numerical code against new and existing experimental data are also included at the end of the Section.

\section{Numerical modelling}

The numerical modelling was carried out with a slightly modified version of the original IH-2VOF code developed by the University of Cantabria (Lara et al., 2011), which solves the 2DV Reynolds Average Navier-Stokes (RANS) equations, based on the decomposition of the instantaneous velocity and pressure fields into average and turbulent components, and tracks the free surface based on the Volum of Fluid (VOF) method. The modification of the IH-2VOF code was recently proposed by Formentin \& Zanuttigh (2018) and regards the outflow boundary condition to include the possibility of representing the wave overtopping process also in case of "dry landward conditions of the structures", i.e. without the presence of the water in-shore the overtopped structures (see, for example, the scheme of 
Figure 1). The use of this version of the code allowed the storage of the overtopping discharge in a reservoir behind the structures, as represented in Figure 2.

To estimate the total overtopping volumes, 4 numerical wave gauges were placed inside the reservoir (see Figure 2). The final levels of the water depth $(h)$ accumulated in the reservoir at the end of the numerical simulations and registered at each gauge were multiplied by the width of the reservoir, deriving thus 4 estimations of the overtopped volumes. The total overtopped volumes are the results of the average of the 4 individual estimations at each gauge. This methodology allows an accurate computation of $q$ also in case the free-surface elevation is still oscillating inside the reservoir at the end of the simulations and provides different values of $h$ at the different gauges.

At the end of the simulations, the average wave overtopping discharge $q$ was calculated dividing the collected volumes by the duration of the simulations themselves. The values of $q$ derived from the reservoirs were also compared to the values of $q$ obtained by integrating the flow velocities $(u)$ with the corresponding water depths $(h)$ registered at 2 gauges placed at the off-shore and in-shore edges of the crown-walls (see Figure 2), obtaining a good agreement of the results from the 2 methods. These estimations of $q$ are conceptually comparable to the measurements of $q$ from the weighing boxes by VD and to the results of the experimental investigations presented below in this contribution.

The incident and the reflected waves were reconstructed from the registrations the surface elevations at 3 numerical wgs placed at approximately 3 wave lengths $\left(L_{m-1,0}\right)$ from the wave maker, following the methodology by Zelt and Skjelbreia (1992).

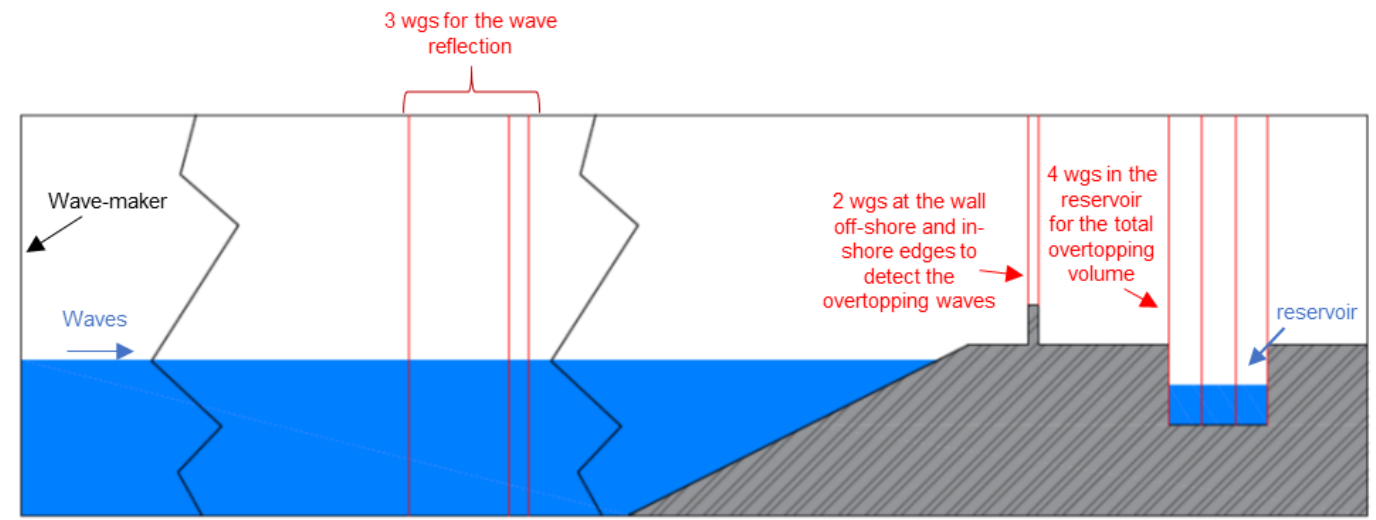

Figure 2. Layout of the numerical wave flume with reference to the position of the wave gauges (wgs) for the measure of the wave reflection and of the overtopping discharge and volume.

\section{Laboratory experiments}

The new campaign of experiments was conducted in the wave flume of the Hydraulic Laboratory of the University of Bologna (see Figure 3) in the winter/spring 2018. The tests were performed in 1:20 model scale in the wave flume of the laboratory, which is $12 \mathrm{~m}$ long, $0.5 \mathrm{~m}$ wide and $1.0 \mathrm{~m}$ deep. It is equipped by a piston-type wave-maker with a special shape, which generates waves by its vertical movements. The wave attacks are regular and irregular generated with a Jonswap spectrum, by defining the wave height $H_{s}$, the wave period $T_{p}$ and the peak enhancement factor $\gamma=3.3$ in all tests. The maximum $H_{s}$ is $0.06 \mathrm{~m}$, the maximum wave length $L_{m-1,0}$ is around $3 \mathrm{~m}$, and the water depth $h$ at the wave-maker should not exceed $0.4 \mathrm{~m}$.

The instruments installed in the wave-flume for the experiments consisted of:

- 3 resistive wave gauges (wgs), characterized by a sample frequency $s f$ of $100 \mathrm{~Hz}$, to record the freesurface elevation and to reconstruct the incident and reflected waves, placed at approximately $1.5 \cdot L_{m}$. ${ }_{10, t}$ from the wave-maker;

- 6 Acoustic Doppler Profilers (ADPs, $s f \approx 20 \mathrm{~Hz}$ ), which were used to measure the flow velocity components and track the water surface along the ramp and over the crest of the structures;

- a recirculation system, which allowed to keep the water level difference within a $\pm 4 \mathrm{~mm}$ range for each test;

- a tank, placed behind the structures and equipped with a hydrometer to measure the overtopping volumes (precision of the hydrometer $\approx 1 \mathrm{~mm}$, corresponding roughly to volumes of $\approx 2$ liters and average discharges of $\approx 1 \cdot 10^{-5} \mathrm{~m}^{3} / \mathrm{s}$ );

- a $25 \mathrm{~Hz}$ GoPro camera employed to film the wave run-up and overtopping process. 
All the structures and the crown walls were realized in a very smooth plywood material, which can be characterized by a roughness factor of $\gamma_{f}=1$ (EurOtop 2007).

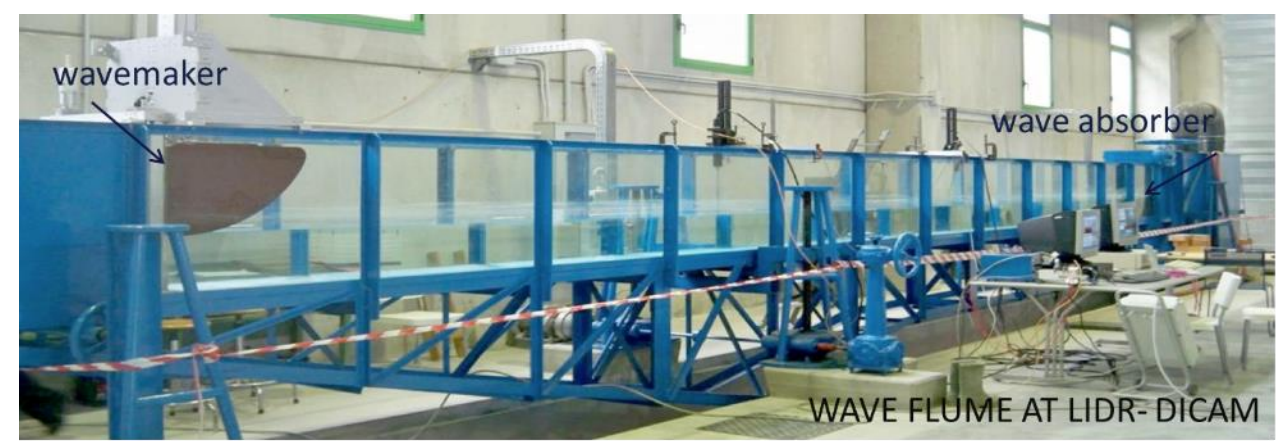

Figure 3. Wave flume equipped with the piston-type wave-maker at the Hydraulic Laboratory of the University of Bologna (LIDR).

\section{Tested configurations and measurements}

The selection of the tested configurations for the new numerical and experimental investigations aimed at extending the work already done on dikes with promenades by VD under non-breaking waves, to smooth structures with a limited crest width and milder slopes under breaking and non-breaking waves.

The numerical database on smooth dikes collected by Formentin et al. (2014) and updated by Formentin \& Zanuttigh (2018) was the starting point for the setup of the new numerical tests. The original set of structures tested by Formentin \& Zanuttigh (2018), consisting of smooth dikes with different offshore slopes $\cot \alpha_{d}(4,6)$, various wall freeboards $R_{c} / H_{s}$ (in the range $[-1.5 ;+1.5]$ ) and constant berm width $B(3 \mathrm{~m})$, was enlarged and modified to include the presence of the crown walls with and without bn, see Figure 1 . The berm widths $B(3,6,9 \mathrm{~m})$, the heights of the crown walls $h_{w}(1.5$ and $2 \mathrm{~m})$, the ratios $\lambda$ between the bn height and the wall height $(0.25 ; 0.3 ; 0.375)$, the inclination $\varepsilon$ of the bn $(30,45$, $\left.60^{\circ}\right)$ and the berm relative emergence $h_{b} / H_{s}(-1.5$ and 0$)$ were set-up in the numerical code following the same values or ranges already investigated by VD.

The numerical simulations consisted of approximately 400-500 irregular waves (1500 s of simulation, with a sample frequency of $20 \mathrm{~Hz}$ ), characterized by Jonswap spectrum $(\gamma=3.3)$, one target wave height $H_{s}=2 \mathrm{~m}$ and various peak wave periods $T_{p}$ to determine wave steepnesses $H_{s} / L_{m-1,0}$ in the range $[0.02 ; 0.04]$. All the values refer to prototype units.

The resulting matrix of the tested conditions for the new numerical investigation is therefore a combination of the wave attacks and structure configurations characterizing the experiments by VD and the numerical simulations by Formentin \& Zanuttigh (2018). The matrix, which overall includes 91 configurations, is here reported in Table 1. In the Table, the values and the ranges of the several parameters are subdivided into 2 groups according to the two different values of $h_{w}(1.5$ and $2 \mathrm{~m})$ characterizing the "low wall" and the "high wall" configurations respectively. Not all the possible combinations of structural and hydraulic parameters were tested.

\begin{tabular}{|l|l|l|l|}
\hline \multicolumn{2}{|c|}{ Table 1. Summary of the tested conditions with the numerical model. Prototype scale units. } \\
\hline Parameter & Description of the parameter (see Fig. 1) & Low wall config. & High wall config. \\
\hline$h_{w}[\mathrm{~m}]$ & Crown wall height & 1.5 & 2.0 \\
$R_{c}[m]$ & Emergence of the crown wall with respect to the swl & 2.5 & $2.0 ; 3.0$ \\
$h_{b}[\mathrm{~m}]$ & Emergence of the berm with respect to the swl & -1.0 & $-1.0 ; 0$ \\
$B[\mathrm{~m}]$ & Berm width & $3.0 ; 6.0 ; 9.0$ & $3 ; 6$ \\
$h[m]$ & Water depth in front of the structure & 7.5 & $8.5 ; 7.5$ \\
$H_{s}[m]$ & Target wave height & 2.0 & 2.0 \\
$H_{s} / L_{m-1,0, t}[-]$ & Target wave steepness & $0.03 ; 0.04$ & $0.02 ; 0.03 ; 0.04$ \\
$\xi_{m-1,0}[-]$ & Breaker parameter based on the spectral wave period & {$[1.36 ; 3.97]$} & {$[1.28 ; 4.26]$} \\
$R_{d} / H_{s}$ & Relative crest freeboard considering the crown wall & 1.25 & $1 ; 1.5$ \\
$h_{b} / H_{s}$ & Relative berm emergence with respect to the swl & -0.5 & $-0.5 ; 0$ \\
$B / L_{m-1,0}[-]$ & Relative berm width width & {$[0.024 ; 0.074]$} & {$[0.013 ; 0.102]$} \\
$\cot \left(\alpha_{d}\right)$ & Cotangent of the off-shore structure slope & $2 ; 3 ; 4$ & $2 ; 3 ; 4$ \\
$\lambda[-]$ & Ratio between the bn height and the crown wall height, & 0.30 & $0.25 ; 0.375$ \\
$\varepsilon\left[{ }^{\circ}\right]$ & $h_{n} / h_{w}(\lambda=0$ means no bn) & $0 ; 30 ; 45 ; 60$ & $0 ; 30 ; 45 ; 60$ \\
$\#$ & Inclination of the bn $(\varepsilon=0$ means no bn) & 32 & 59 \\
\hline
\end{tabular}


The model scale (1:20), the wave attack characteristics and the structure configurations tested in the laboratory have been selected based on the preliminary information gathered with the numerical simulations (Table 1) and limitedly to the physical constraints imposed by the facility (see above). The set-up included 4 dike configurations, by combining 2 horizontal berm widths $(B=3$ and $6 \mathrm{~m})$ and 2 structure slopes $\left(\cot \left(\alpha_{d}\right)=2\right.$ and 4$)$. For each, 4 further configurations were investigated, by placing 2 wall heights $\left(h_{w}=0.8\right.$ and $1 \mathrm{~m}$, respectively the "low-wall" and the "high-wall" configurations in Table 2) with and without bn $\left(\varepsilon=0\right.$ and $30^{\circ}, \lambda=0$ and 0.375$)$ at the in-shore edge of the berms. For each of the 16 structure configurations, 2 target wave heights $\left(H_{s}=1\right.$ and $\left.1.2 \mathrm{~m}\right), 2$ target wave steepnesses $\left(H_{s} / L_{m}\right.$ ${ }_{1,0}=0.02$ and 0.03$)$ and 2 berm emergences $\left(h_{b} / H_{s}=-0.5\right.$ and 0$)$ were tested. Overall, 118 tests were performed. A few conditions were not tested because the expected overtopping discharge was lower than the minimum measurable due to the lab facility $\left(q<5 \cdot 10^{-5} \mathrm{~m}^{3} /(\mathrm{sm})\right.$, scale $\left.1: 20\right)$.

Each test lasted $480 \mathrm{~s}$, corresponding to a number of waves varying between 350 and 500, according to the test characteristic $T_{p}$. The matrix of the tested conditions is reported in Table 2.

\begin{tabular}{|l|l|l|l|}
\hline \multicolumn{5}{|l|}{ Table 2. Summary of the tested conditions in the laboratory. Prototype scale units. } \\
\hline Parameter & \multicolumn{1}{|c|}{ Description of the parameter (see Fig. 1) } & \multicolumn{1}{l|}{ Low wall config. } & High wall config. \\
\hline$h_{w}[\mathrm{~m}]$ & Crown wall height & 0.8 & 1.0 \\
$R_{c}[\mathrm{~m}]$ & Emergence of the crown wall with respect to the swl & $0.8 ; 1.3 ; 1.4$ & $1 ; 1.5 ; 1.6$ \\
$h_{b}[\mathrm{~m}]$ & Emergence of the berm with respect to the swl & $-0.6 ;-0.5 ; 0$ & $-0.6 ;-0.5 ; 0$ \\
$B[\mathrm{~m}]$ & Berm width & $3 ; 6$ & $3 ; 6$ \\
$h[m]$ & Water depth in front of the structure & $6.4 ; 6.5 ; 7$ & $6.4 ; 6.5 ; 7$ \\
$H_{s}[m]$ & Target wave height & $1.0 ; 1.2$ & $1.0 ; 1.2$ \\
$H_{s} / L_{m-1,0}[-]$ & Target wave steepness & $0.03 ; 0.04$ & $0.03 ; 0.04$ \\
$\xi_{m-1,0}[-]$ & Breaker parameter based on the spectral wave period & {$[1.20 ; 3.28]$} & {$[1.27 ; 3.28]$} \\
$R_{d} / H_{s}$ & Relative crest freeboard considering the crown wall & $0.67 ; 0.8 ; 1.17 ; 1.3$ & $0.83 ; 1 ; 1.33 ; 1.5$ \\
$h_{b} / H_{s}$ & Relative berm emergence with respect to the swl & $-0.5 ; 0$ & $-0.5 ; 0$ \\
$B / L_{m-1,0}[-]$ & Relative berm width with & {$[0.055 ; 0.238]$} & {$[0.055 ; 0.226]$} \\
$\cot \left(\alpha_{d}\right)$ & Cotangent of the off-shore structure slope & $2 ; 4$ & $2 ; 4$ \\
$\lambda[-]$ & Ratio between the bn height and the crown wall height, & $0 ; 0.375$ & $0 ; 0.375$ \\
$\varepsilon\left[{ }^{\circ}\right]$ & $h_{n} / h_{w}(\lambda=0$ means no bn) & $0 ; 30$ & $0 ; 30$ \\
$\#$ & Inclination of the bn $(\varepsilon=0$ means no bullnose) & 62 & 56 \\
\hline
\end{tabular}

\section{Validation of the numerical model}

The numerical model has been validated by reproducing 4 tests selected from the database by VD and 7 of the new tests carried out in the laboratory of Bologna (tests "BO", hereinafter). The characteristics of the tests, reported in Table 3 in model scale units, cover a variety of wave attacks and structure cross-sections selected to verify the performance of the numerical code against a set of configurations representative of the variety of the test conditions simulated. To this purpose, all the 11 selected tests consist of dikes with berm and walls characterized by different values of $\cot \left(\alpha_{d}\right), B, h_{b}, R_{c}$, and $h_{w}$. The test VD \#1 (see Table 3), belonging to the VD-dataset, includes also the bn $\left(\varepsilon=45^{\circ}, \lambda=0.375\right)$.

\begin{tabular}{|c|c|c|c|c|c|c|c|c|c|c|}
\hline Test ID & $\cot \left(\alpha_{d}\right)$ & $h[\mathrm{~m}]$ & $\mathrm{H}_{\mathrm{m} 0}[\mathrm{~m}]$ & $T_{m-1,0}[\mathrm{~s}]$ & $h_{b}[\mathrm{~m}]$ & $B[\mathrm{~m}]$ & $R_{c}[\mathrm{~m}]$ & $h_{w}[\mathrm{~m}]$ & $\lambda[-]$ & $\varepsilon\left[^{\circ}\right]$ \\
\hline VD \#1 & 2 & 0.42 & 0.158 & 1.660 & -0.173 & 0.667 & 0.233 & 0.06 & 0 & 0 \\
\hline VD \#2 & 2 & 0.48 & 0.101 & 1.423 & -0.067 & 0.333 & 0.147 & 0.08 & 0 & 0 \\
\hline VD \#3 & 2 & 0.43 & 0.159 & 2.053 & -0.117 & 0.333 & 0.197 & 0.08 & 0 & 0 \\
\hline VD \#4 & 2 & 0.43 & 0.159 & 2.053 & -0.117 & 0.333 & 0.197 & 0.08 & 0.375 & 45 \\
\hline BO \#1 & 4 & 0.35 & 0.049 & 1.048 & 0 & 0.3 & 0.050 & 0.050 & 0 & 0 \\
\hline BO \#2 & 2 & 0.35 & 0.065 & 1.271 & 0 & 0.3 & 0.050 & 0.050 & 0 & 0 \\
\hline BO \#3 & 2 & 0.325 & 0.069 & 1.052 & -0.025 & 0.3 & 0.075 & 0.050 & 0 & 0 \\
\hline BO \#4 & 2 & 0.35 & 0.053 & 1.048 & 0 & 0.15 & 0.050 & 0.050 & 0 & 0 \\
\hline BO \#5 & 2 & 0.325 & 0.059 & 1.116 & -0.025 & 0.15 & 0.075 & 0.050 & 0 & 0 \\
\hline BO \#6 & 4 & 0.325 & 0.052 & 1.076 & -0.025 & 0.15 & 0.075 & 0.050 & 0 & 0 \\
\hline BO \#7 & 4 & 0.35 & 0.050 & 1.066 & 0 & 0.15 & 0.050 & 0.050 & 0 & 0 \\
\hline
\end{tabular}

The results of the validation are qualitatively reported here in Figure 4, by comparing the measured and numerical dimensionless values of $q, q / g H_{m 0} T_{m-1,0}$. In the Figure, some of the tests belonging to the BO-dataset have been represented with the same symbol (e.g. BO \#2 and BO \#3) because they correspond to the same structure cross-section subjected to different waves. By comparing these couples of tests the numerical model tends on average to slightly over-predict the tests with the berm at the swl $\left(h_{b}=0\right)$ and slightly under-predict the tests with emerged berms $\left(h_{b}<0\right)$. The predictions of the VD-tests are randomly 
distributed around the line of the perfect agreement and do not show any significant bias against specific parameters. The level of agreement among measurements and numerical values ca be represented by values of the determination coefficient $R^{2}$ equal to 0.85 and 0.64 for the datasets VD and BO, respectively.

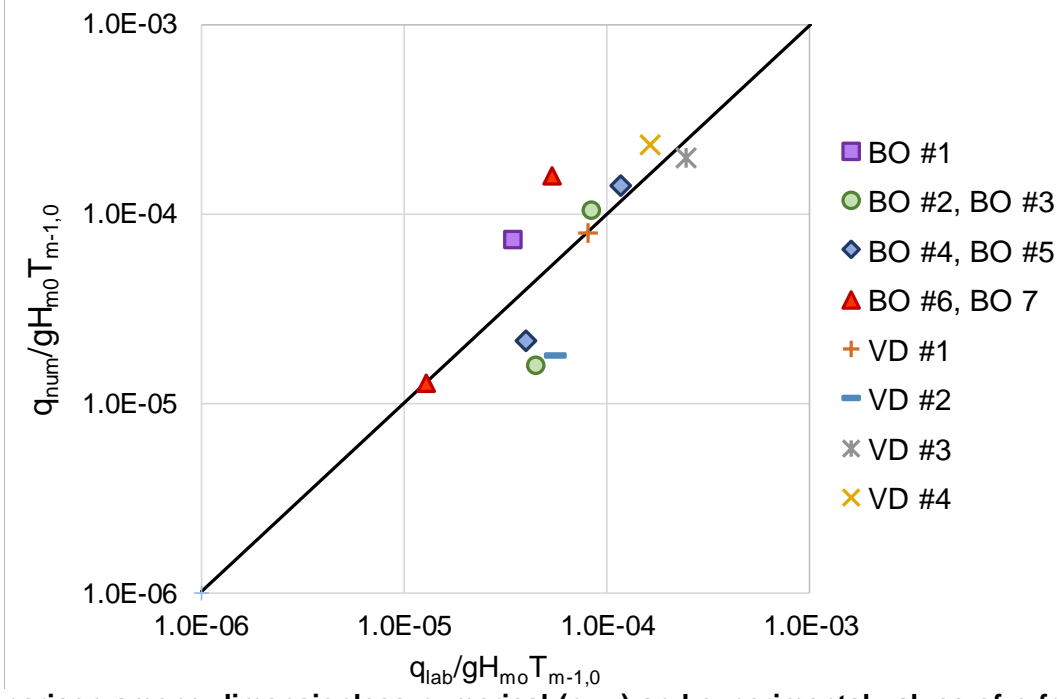

Figure 4. Comparison among dimensionless numerical $\left(q_{\text {num }}\right)$ and experimental values of $q$ from the dataset by VD and from the new experiments at the University of Bologna $\left(q_{l a b}\right)$.

\section{EFFECTS OF THE BULLNOSE}

The new numerical and laboratory experience collected has been used to carry out an in-depth sensitivity analysis to the effects of the bns $(\lambda, \varepsilon)$ in combination to other structural parameters $\left(\cot \left(\alpha_{d}\right)\right.$, $\left.R_{c}, B, h_{b}\right)$. To this purpose, the values of $q$ resulting from different structure configurations subjected to the same wave attack $\left(H_{s}\right.$ and $\left.T_{m-1,0}\right)$ have been compared each other.

The most relevant results of the sensitivity analysis are synthesized in the following with reference to the example case of Figure 5, which reports the dimensionless $q$ values calculated for 28 numerical simulations obtained by running the same wave $\left(H_{s}=2 \mathrm{~m}, H_{s} / L_{m-1,0}=3 \%\right)$ with the same water level $(h=7.5$ $\mathrm{m})$ against a structure characterized by the same berm emergence $\left(h_{b} / H_{s}=0.5\right)$ and the same wall height $\left(h_{w}=2 \mathrm{~m}\right)$ but different slopes $\left(\cot \left(\alpha_{d}\right)=4,3\right.$ and 2$)$, berm widths $(B=3,6 \mathrm{~m})$ and bns $(\lambda=0,0.375,0.25$; $\left.\varepsilon=0,30,45,60^{\circ}\right)$.

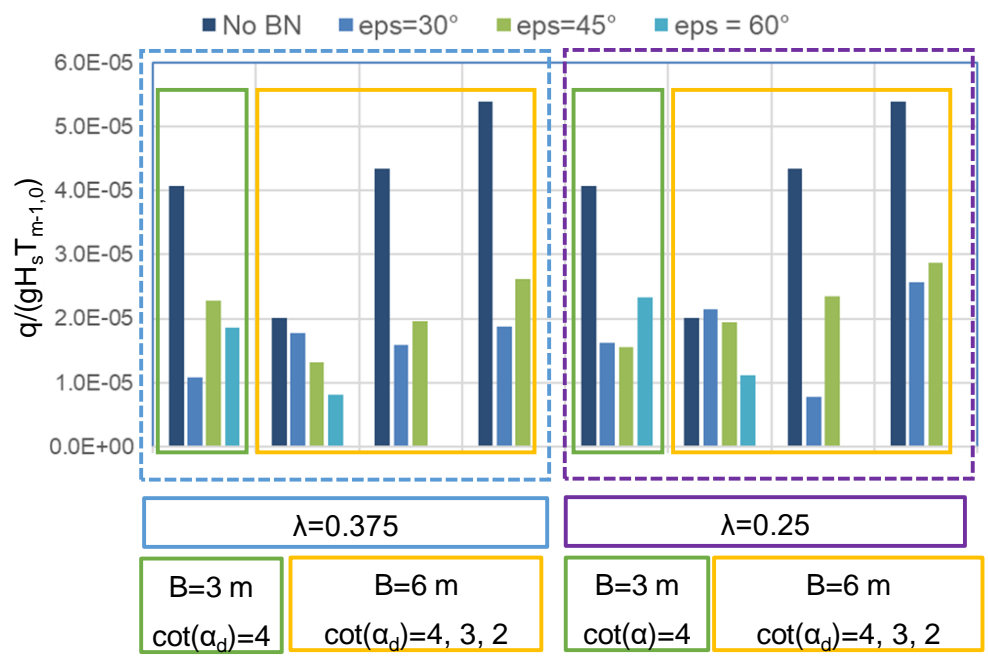

Figure 5. Dimensionless overtopping discharges $\left(q / \mathrm{g} H_{s} T_{m-10}\right)$ for a given wave attack (same target values of $H_{s}$ and $\left.T_{m-1,0}\right)$ and different structure geometries. Data from the numerical modelling. 
In Figure 5, the $q$-values relative to the 28 tests are displayed on vertical bars of different colours according to the value of $\varepsilon$ (when there is no bn, $\varepsilon=0$ ) and grouped in various frames according to the corresponding values of $\lambda, B$ and $\cot \left(\alpha_{d}\right)$. All the bars grouped in the same parameter-frame are characterized by the same value of the parameter (e.g., all the bars enclosed by the green frame present $B=3 \mathrm{~m}$ and $\cot \left(\alpha_{d}\right)=4$, while all the bars enclosed by the dashed magenta are characterized by $\lambda=0.25$, with the exception of the dark blue bars which have no bn, and therefore $\lambda=0$ ).

Based on the analysis of the quantitative results collected in Figure 5 (and in similar charts which can be derived for other wave attack conditions), the following operative indications for the best bn configuration can be drawn:

- the presence of the bn induces a reduction of $q$ variable between $\approx 15$ and $35 \%$; the entity of the reduction is comparable for the same test in breaking $\left(\xi_{m-1,0} \leq 1.8\right)$ and non-breaking conditions $\left(\xi_{m-1,0}>1.8\right)$.

- the best bn inclination seems to be $\varepsilon=30^{\circ}$; by further increasing $\varepsilon$ apparently, no relevant further reduction of $q$ is achieved;

- the effect of $\lambda$ is marginal, i.e. a very similar effect is observed by modifying the value of $\lambda$ from 0.375 to 0.25 ;

- $\quad$ in case of walls without a bn, the berm width plays a non-negligible role in the reduction of $q$ (the wider $B$, the lower $q$ ); however, in case of walls with bn, wide berms ( $B=6$ or $9 \mathrm{~m}$ ) tend to reduce the effect of the bn (the reduction of $q$ is $\approx 5-10 \%$ ). In conclusion, the combination of bn and berm is more effective in case of short berms.

Another important issue concerning the efficiency of the bn (which cannot be deduced from Fig. 5) is related to the entity of the overtopping rate itself. The reduction of $q$ due to the presence of the bn is less effective for higher for more frequently overtopped structures, i.e. is for smaller $R_{c} / H_{s}$ or $h_{w} / R_{c}$

\section{WAVE OVERTOPPING DISCHARGE: COMPARISON WITH EXISTING FORMULAE}

This Section presents and discusses the results of the new numerical and experimental investigations. Firstly, a literature overview on the available predicting methods of $q$ is provided, in order to introduce and ease the interpretation of the new data in comparison with the existing formulae. Then, the adequacy of the formulae by VD for non-breaking waves is checked and extended to the new structure configurations. A new reduction coefficient is also proposed for breaking waves.

\section{Literature overview}

The most recent and complete method to predict $q$ at composite structures with walls and bn is based on the EurOtop (2016) equations 5.10 and 5.11, respectively valid for breaking and non-breaking waves, i.e. for values of the breaker parameter $\xi_{m-1,0}$ respectively $\leq$ and $>$ than 1.8. The EurOtop's Eq.s 5.10 and 5.11 are reported in the following as Eq.s (1) and (2):

$$
\begin{gathered}
\left.\frac{q}{\sqrt{g H_{m 0}^{3}}}=\frac{0.023}{\sqrt{\operatorname{tan\alpha _{d}}}} \cdot \gamma_{b} \cdot \xi_{m-1,0} \cdot \exp \left(-\left(2.7 \cdot \frac{R_{c}}{\xi_{m-1,0} \cdot H_{m 0} \cdot \gamma_{b} \cdot \gamma_{f} \gamma_{\beta} \cdot \gamma_{v}}\right)\right)^{1.3}\right), \xi_{m-1,0} \leq 1.8 \\
\frac{q}{\sqrt{g H_{m 0}^{3}}}=0.09 \cdot \exp \left(-\left(1.5 \cdot \frac{R_{c}}{H_{m 0} \cdot \gamma_{f} \gamma_{\beta} \cdot \gamma^{*}}\right)^{1.3}\right), \xi_{m-1,0}>1.8
\end{gathered}
$$

The coefficients $\gamma_{\beta}, \gamma_{f}, \gamma_{b}$ account for, respectively, the wave obliquity, the structure roughness and the presence of a berm. The effects of crown walls and bns are differently represented in the two formulations.

In case of non-breaking waves Eq. (2) accounts for the contemporary effects of wall, berm and bn through the coefficient $\gamma^{*}$, whose formulation varies in relation to the combination of the structural elements (wall and berm, wall and bn, wall, bn and berm, etc.). The formulations for $\gamma^{*}$ are the result of the work by VD and are synthesized in the EurOtop equations 5.45 to 5.51. In general, $\gamma^{*}$ can be expressed as a function of the following parameters:

$$
\gamma^{*}=f\left(\frac{h_{w}}{R_{c}}, \frac{B}{L_{m-1,0}}, \lambda, \varepsilon\right) .
$$

The formulations and the adequacy of the coefficient $\gamma^{*}$. 
As for breaking waves, the current approach accounts exclusively for the effects of a storm wall through the coefficient $\gamma_{v}$ in Eq. (1). Two formulations of $\gamma_{v}$ are proposed in the two editions of the EurOtop manual. The formulation of EurOtop (2007)

$$
\gamma_{\mathrm{v}, 2007}=1.35-0.0078 \cdot \alpha_{w}
$$

has been introduced by Van der Meer (1997) based on the analyses of the so-called "Harlingen dataset" (Den Heijer, 1998), a set of overtopping experiments against slopes with crown walls which have their foot under the still water level. The formulation of EurOtop (2016),

$$
\gamma_{\mathrm{v}, 2016}=\exp \left(-0.56 \cdot \frac{h_{w}}{R_{c}}\right)
$$

is the expression proposed by VD to account for the wall in case of non-breaking waves and it is one of the formulations contributing to the definition of $\gamma^{*}$. Eq. (4) corresponds to Eq. 5.31 in EurOtop (2007), while Eq. (5) corresponds to Eq. 5.45 in EurOtop (2016). Eq. (4) is valid for wall angles between $45^{\circ}$ and $90^{\circ}$ and therefore it may not be used for negative angles as for a bn. Van Doorslaer et al. (2016) verified that the expression for non-breaking waves by Eq. (5) is still valid also for breaking waves in case of walls with the foot above the SWL. However, no systematic study on the effects of walls with emerged foot, berm and bns under breaking waves has been carried out so far and no specific coefficient alike $\gamma^{*}$ has been defined yet.

\section{Non-breaking waves}

The new experimental and numerical values of $q$ corresponding to non-breaking conditions are compared in the following to Eq. (2), with $\gamma^{*}$ expressed as in Eq. (3). To this purpose, only the tested conditions characterized by $\xi_{m-1,0}>1.8$ have been considered (overall 121 tests). The values of the coefficients $\gamma_{\beta}$ and $\gamma_{f}$ of Eq. (2) are always equal to 1, as all the tests consisted of perpendicular wave attacks against smooth structures exclusively.

The data are compared to the curve representing Eq. (2) in Figure 6, which displays the results of the experiments in terms of $q /\left(g H^{3}\right)^{0.5}$ as functions of $R_{c} /\left(H_{m 0} \cdot \gamma^{*}\right)$. The results are distinguished between tests without bn (orange circles) and with bn (green diamonds). In this Figure, most of the data are well aligned along the fitting curve and all the points but one are included within the $90 \%$ confidence bands associated to the formulae (dotted lines). A few data with bn around $R_{c} /\left(H_{m 0} \gamma^{*}\right)=3$ are slightly underestimated by the formulae. All these tests belong to the numerical dataset and are characterized by values of the measured wave steepness $H_{m 0} / L_{m-1,0}<0.015$ (being the target wave steepness $H_{s} / L_{m-1,0}=0.02$ ) which are close or out of the limits of validity of Eq.s (1) and (2) defined by $H_{s} / L_{m-1,0}=[0.01 ; 0.05]$. Therefore, the underestimation can be explained by considering these tests either "not reliable", due to the significant difference between the target and the measured wave steepness, or out of the range of applicability of the formulae. Overall, the existing approach for non-breaking waves by VD accurately fits the new data and no correction is required.

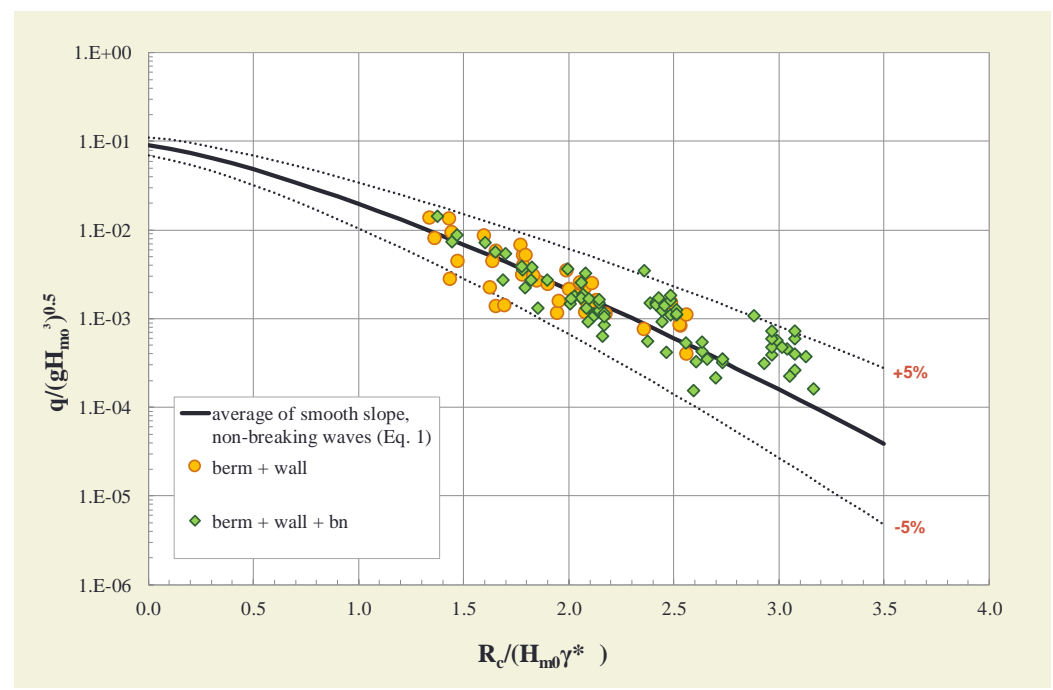

Figure 6. Dimensionless overtopping discharges $q /\left(\mathrm{gH}_{m 0}^{3}\right)^{0.5}$ as functions of the relative crest freeboard $\boldsymbol{R}_{d} / \boldsymbol{H}_{m 0}$ compared to the curve representing the EurOtop (2016) formulae for the prediction of $q$ in case of slopes with berm, wall and bn for non-breaking conditions (Eq.s 1 and 2). 


\section{Breaking waves}

The remaining 83 tests relative to breaking conditions $\left(\xi_{m-1,0} \leq 1.8\right)$ are compared in this Sub-section to Eq. (1). Similarly to the analysis on non-breaking waves, the data are compared to the curves representing the formula in Figure 7. The ordinate values in the Figure are the dimensionless discharges $q /\left(g H_{m 0}\right)^{0.5} \cdot\left(\tan \alpha_{d} \cdot H_{m 0} / L_{m-1,0}\right)^{0.5} \gamma_{b}$, while two different expressions have been considered to formulate the coefficient $\gamma_{v}$ of Eq. (1) and therefore to build the abscissa values for the plot:

- $\quad$ in Figure 7-a, $\gamma_{v}$ is expressed as in EurOtop (2016), i.e. based on Eq. (5), leading to the abscissa $R_{c} /\left(H_{m 0} \cdot \xi_{m-1,0} \cdot \gamma_{b} \cdot \gamma_{f} \cdot \gamma_{\beta} \cdot \gamma_{v, 2016}\right)$

- $\quad$ in Figure 7-b, $\gamma_{v}$ is replaced by the coefficient $\gamma^{*}$, expressed in Eq. (3), in order to check the effect of applying also to breaking waves all the reduction coefficients defined by VD for non-breaking waves; the abscissa in this case becomes thus $R_{c} /\left(H_{m 0} \cdot \xi_{m-1,0} \cdot \gamma_{b} \cdot \gamma_{f} \cdot \gamma_{\beta} \cdot \gamma^{*}\right)$.

Based on the analysis of the charts a and b of Figure 8, the following considerations can be drawn:

- the application of $\gamma_{v}$ as formulated in (5) provides an accurate representation of the new without bn, see the chart b; the use of Eq. (5) is therefore recommended in case of breaking waves against slopes with berm and wall, where the foot of the wall is above the SWL. This conclusion is in agreement with Van Doorslaer et al. (2016).

- The bn has a non-negligible effect in the reduction of the overtopping discharge also in case of breaking waves. The coefficient $\gamma_{v}$ as formulated in Eq. (5) is not sufficient to account also for the presence of the bn, as all the tests with bn are systematically overestimated by the formulae, see the chart a.

- The effect of the bn is though lower for breaking than for non-breaking waves. Chart b indicates that the use of $\gamma^{*}$ instead of $\gamma_{v}$ eliminates the bias between the 2 distributions of data with and without bn, but leads to the systematic under-prediction of the data.
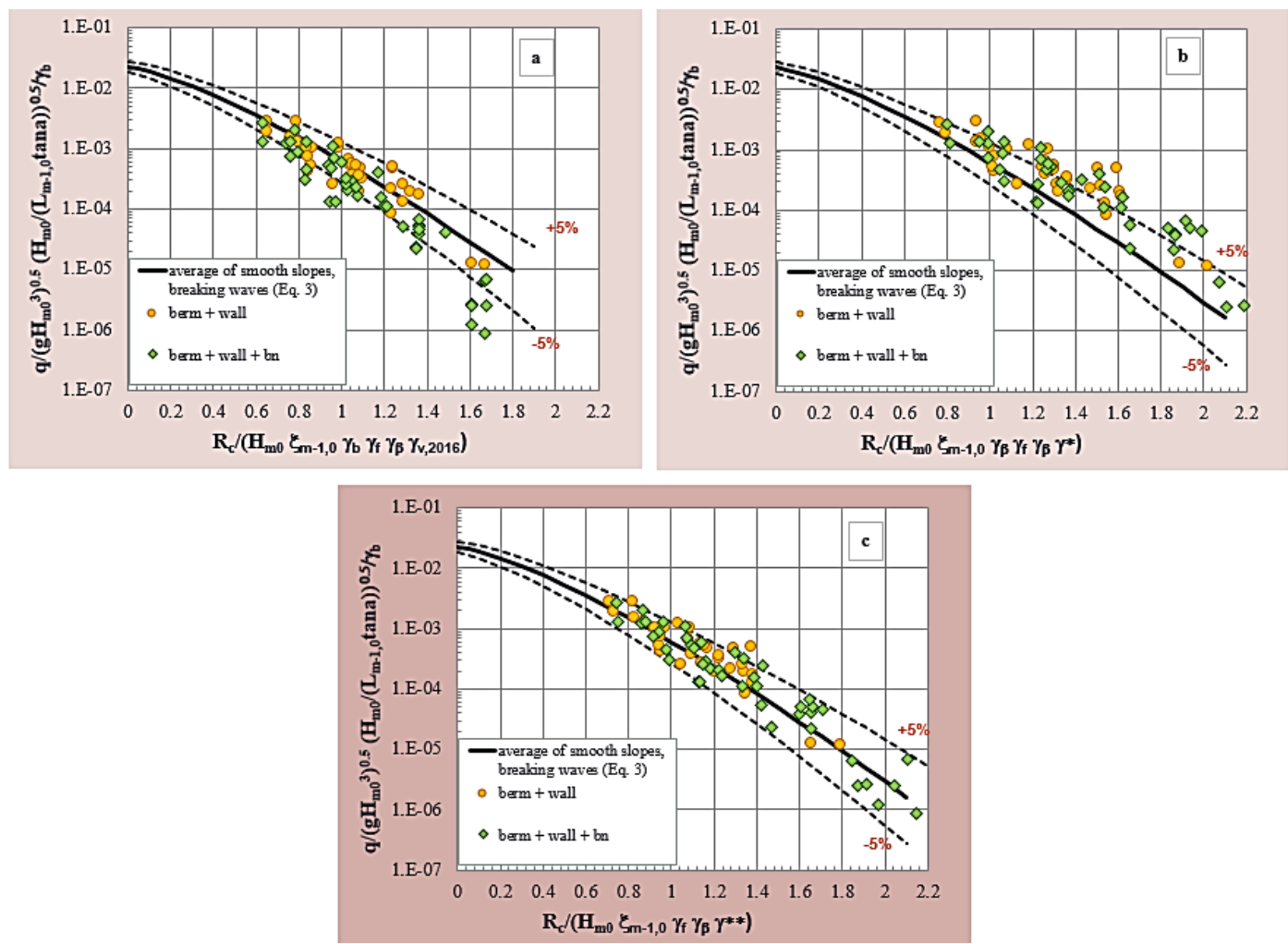

Figure 7. Dimensionless overtopping discharges $q /\left(\mathrm{gH}^{3}{ }_{m 0}\right)^{0.5}$ as functions of the relative crest freeboard $\boldsymbol{R}_{c} / \boldsymbol{H}_{m 0}$ compared to the curve representing the EurOtop (2016) formulae for the prediction of $q$ in case of slopes with berm, wall and bn for non-breaking conditions (Eq.s 1 and 2).

Since neither $\gamma_{v}$ nor $\gamma^{*}$ give a fully satisfactory representation of the breaking tests, the following new correction factor is proposed:

$$
\gamma^{* *}=\frac{\gamma^{*}}{\tanh \left(\xi_{m-1,0}\right)}
$$


where $\gamma^{*}$ is the reduction coefficient derived by VD and here summarized in Eq. (3). The coefficient $\gamma^{* *}$ of Eq. (6) is meant to replace the coefficient $\gamma_{v}$ in Eq. (1) and the $\gamma^{*}$ coefficient in Eq. (2). Indeed, its formulation is conceived to be directly applicable also to the non-breaking waves represented by Eq. (2) as the denominator $\tanh \left(\xi_{m-10}\right)$ goes to 1 when $\xi_{m-10}$ goes to $+\infty$, and in the practice its value is sufficiently close to 1 already for $\xi_{m-10}>2$, i.e. approximately when the non-breaking condition is reached. $\gamma^{* *}$ basically reproduces the effect of $\gamma^{*}$ in a reduced version for breaking waves and corresponds to $\gamma^{*}$ for non-breaking waves.

The results of the application of $\gamma^{* *}$ are qualitatively shown in Figure 7-c and Figure 8 for breaking and non-breaking waves respectively. In Figure $7-\mathrm{c}, \gamma^{* *}$ is applied to the new tests and it is included in the abscissa of the diagram in place of $\gamma_{v}$. By comparing Figure 7-c to the corresponding charts $\mathrm{a}, \mathrm{b}$ of Figure 8 , it can be appreciated how $\gamma^{* *}$ provides a significant improvement in the representation of both the test with and without bn. All the data but one are included in the $90 \%$ confidence bands around the average predicting curve and no bias is evident.

Figure 8 shows instead the application of $\gamma^{* *}$ to the original dataset by VD used to calibrate $\gamma^{*}$ and to the new tests in non-breaking conditions. This chart can be compared to Figure 6 of the present article as regards the distribution of the new tests and to Figure 5.46 of EurOtop (2016) as regards the tests by VD. Both the comparisons show no evident or significant difference between the application of $\gamma^{*}$ and of $\gamma^{* *}$.

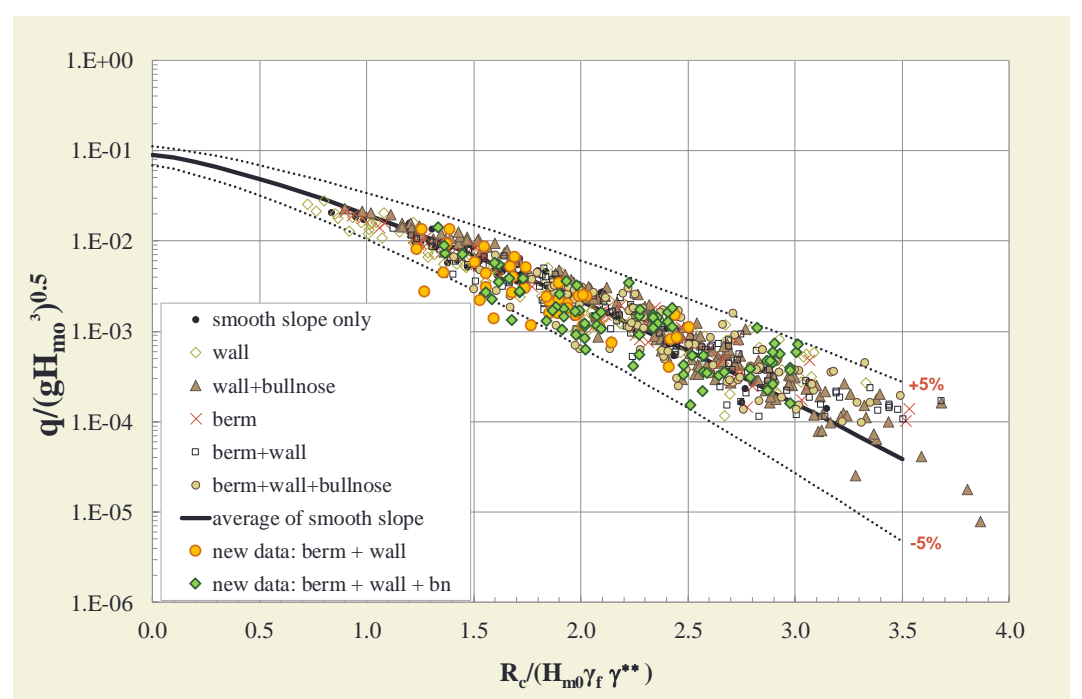

Figure 8. Dimensionless overtopping discharges $q /\left(\mathrm{gH}^{3}{ }_{\mathrm{mo}}\right)^{0.5}$ as functions of the relative crest freeboard $\boldsymbol{R}_{d} / \boldsymbol{H}_{m 0}$ compared to the curve representing the EurOtop (2016) formulae for the prediction of $q$ in case of slopes with berm, wall and bn for non-breaking conditions (Eq.s 1 and 2).

The quantitative assessment of the performance achieved by employing the different formulations of $\gamma$ to predict the values of $q$ for the several datasets is provided in Table 4 , which reports the coefficients of determination $R^{2}$ calculated among measurements and predictions. The indices in the Table confirm that, the most accurate estimations for breaking waves are obtained with $\gamma^{* *}\left(R^{2}=0.88\right)$, while for nonbreaking waves, the predictions obtained with $\gamma^{*}$ and $\gamma^{* *}$ are similarly accurate.

\begin{tabular}{|l|l|}
\hline $\begin{array}{l}\text { Table 4. } \mathbf{R}^{2} \text { values among measurements and } \\
\text { predictions of } \boldsymbol{q} \text { for different datasets and different } \\
\text { formulations of the bullnose reduction factor } \boldsymbol{r} \text {. }\end{array}$ \\
\hline Dataset: BO, breaking waves \\
\hline Eq.(1) + Eq.(5): $\gamma_{v, 2016}$ & 0.86 \\
Eq.(1) + Eq.(3): $\gamma^{*}$ & 0.84 \\
Eq.(1) + Eq.(6): $\gamma^{* *}$ & 0.88 \\
\hline Dataset: Bo, non-breaking waves \\
\hline Eq.(2) + Eq.(3): $\gamma^{*}$ & 0.72 \\
Eq.(2) + Eq.(6): $\gamma^{* *}$ & 0.71 \\
\hline Dataset VD (non-breaking waves) \\
\hline Eq.(2) + Eq.(3): $\gamma^{*}$ & 0.954 \\
Eq.(2) + Eq.(6): $\gamma^{* *}$ & 0.958 \\
\hline
\end{tabular}




\section{APPLICATION OF THE EUROTOP ANN}

This Section presents the application of the EurOtop ANN (Zanuttigh et al., 2016-a; Formentin et al., 2017) to the prediction of the $q$ values related to the new experimental and numerical BO data (Tables 1 and 2) and to the existing data by VD on structures with bn.

\section{The EurOtop ANN}

In order to apply the ANN tool to the new sets of data it is necessary to schematize the geometry of the tested cross-sections following the same scheme used to train the ANN, viz the same scheme adopted within the new EurOtop (2016) database. Figure 1 provides reference to this scheme and to the main ANN input parameters. Further information and details about the mentioned symbols and the ANN input parameters can be found in Zanuttigh et al. (2016-a).

Based on the 15 input parameters composing the present ANN input set, the presence and the effects of the bn are accounted only in $\cot \left(\alpha_{\text {incl }}\right)$, which in turns depends on $\cot \left(\alpha_{u}\right)$. It is worthy to recall that the ANN tool was trained on structures without bn exclusively (Zanuttigh et al., 2016-a and Zanuttigh et al., 2016-b). As in-depth discussed and investigated in Formentin \& Zanuttigh (in press), applying the ANN to data different from the ones used in training is equivalent to extrapolate results, which may lead to more or less unreliable predictions.

The results of the application are qualitatively provided in Figure 9 as comparison among ANN predictions $\left(q_{A N N}\right)$ and measurements (respectively $q_{l a b, n u m}$ for the $\mathrm{BO}$ tests and $q_{V D}$ for the data by VD). In this Figure, the data are distinguished between structures with and without bn. The red dashed lines of Figure 9 correspond to the $95 \%$ confidence bands associated to the predictions. The quantitative results are reported in Table 5 (column "Original input parameters") in terms of rmse, Willmott index WI and $R^{2}$. In order to provide a benchmark case, the average performance of the optimized ANN is reported in the last 3 lines of Table 5 in terms of error indices and in Figure 9 in terms of 95\% confidence bands (black dashed lines).
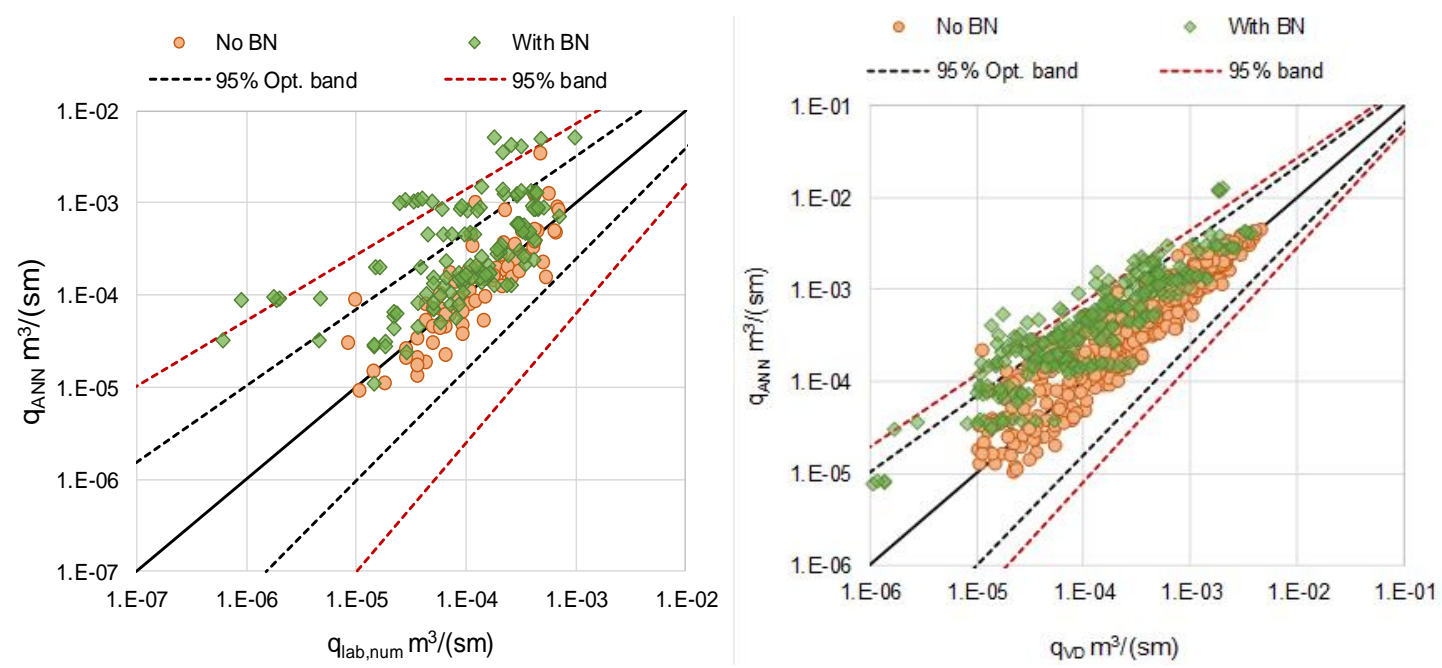

Figure 9. Comparison among ANN predictions $\left(q_{A N N}\right)$ and measurements relative to the BO tests $\left(q_{\text {lab,num, }}\right.$ left panel) and to the test by VD ( $q_{V D}$, right panel). Predictions derived by the original ANN input parameters not accounting for the presence of the bn. Data distinguished between structures with and without bn.

\begin{tabular}{|c|c|c|}
\hline \multicolumn{3}{|c|}{ BO dataset } \\
\hline $\begin{array}{l}r m s e \\
W I \\
R^{2}\end{array}$ & $\begin{array}{l}\text { Original input parameters } \\
0.091 \\
0.525 \\
-\end{array}$ & $\begin{array}{l}\text { Modified input parameters } \\
0.046 \\
0.873 \\
0.60\end{array}$ \\
\hline \multicolumn{3}{|c|}{ VD dataset } \\
\hline $\begin{array}{l}r m s e \\
W I \\
R^{2}\end{array}$ & $\begin{array}{l}\text { Original input parameters } \\
0.064 \\
0.848 \\
0.48\end{array}$ & $\begin{array}{l}\text { Modified input parameters } \\
0.039 \\
0.945 \\
0.81\end{array}$ \\
\hline \multicolumn{3}{|c|}{ Average performance of the ANN (benchmark) } \\
\hline & $\begin{array}{l}0.047 \pm 0.002 \\
0.977 \pm 0.003 \\
0.92 \pm 0.01\end{array}$ & \\
\hline
\end{tabular}


Both the quantitative and the qualitative analyses of the results indicate that:

- the tests belonging to the dataset by VD are overall better represented than the $\mathrm{BO}$ tests; indeed the performance of the ANN when applied to the VD data is relatively close to the performance of the optimized ANN. This can be explained by considering that all the tests without bn by VD have been used for training the ANN.

- The new tests (Fig. 9, left) relative to structures without bn (circles) are sensibly better represented than the BO tests with bn (diamonds), which are the responsible of the very low ANN performance associated to the new tests ( $r m s e=0.091, W I=0.525$, see Table 5). The good representation of the BO tests without bn is particularly significant as these data have been not included in the ANN training.

- Both considering the BO and the VD tests, the ANN tends to systematically overestimate the $q$ values in case of structures with bn;

- overall, the over-predictions associated to the new tests (Fig. 9, left) show more scatter while the over-predictions associated to the VD tests (Fig. 9, right) tend to be more biased (several clusters of data aligned on almost horizontal lines are visible).

These results suggest that the ANN provides a good representation of the (new and existing) tests without bn, while it systematically overestimates the discharge in case of structures with bn. This was easily predictable as the geometry of the bn is not represented in the ANN input set, i.e. the ANN "does not see" the bn.

\section{Representation of the bullnose}

To account for the presence of the bn without retraining the ANN tool, a correction to the representation of the data has been investigated. The idea is to reduce the ANN overestimations of $q$ by increasing the input values of $R_{c}$ and $B$ by considering an equivalent crest freeboard $R_{c, e q}$ and equivalent berm width $B_{e q}$ as depicted in Figure 10 . The modified parameters $R_{c, e q}$ and $B_{e q}$ have been calculated based on the following expressions:

$$
\begin{gathered}
B_{e q}=B+2 \cdot h_{n}^{*} \cdot \tan (\varepsilon), \\
R_{c, e q}=R_{c}-h_{n}^{*}+\frac{h_{n}^{*}}{\cos (\varepsilon)},
\end{gathered}
$$

which should account for the "longer" distance to be travelled by the incident waves along the bn to overtop the wall. However, the reduction of the overtopping discharge induced by the bn is also determined by the overturning effect on the overtopping waves. To account for this extra-reductive contribution, a further modification is included in the input parameters:

$$
\gamma_{f, e q}^{\prime}=\gamma_{f}^{\prime}-0.1 \text {. }
$$

Eq. (9) introduces an equivalent roughness factor $\gamma_{f, e q}$ which is reduced of 0.1 with respect to the original $\gamma_{f}^{\prime}$ and should therefore lead the ANN to predict lower $q$ values. The value of 0.1 has been calibrated on the basis of the available datasets, i.e. the datasets VD and BO, therefore the validity of Eq. (4) is so far limited to smooth structures $\left(\gamma_{f}^{\prime}=1\right)$ exclusively.

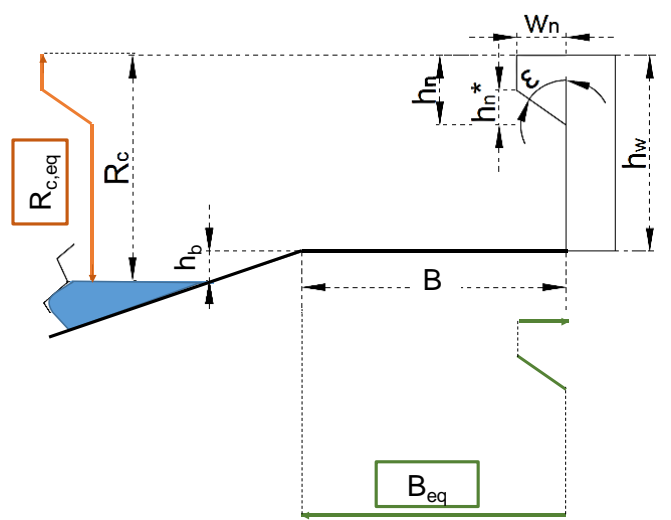

Figure 10. Equivalent parameters adopted to account for the presence of the bullnoses in the setup of the ANN input parameters. 
The results of the application of the ANN tool with the modified input parameters are reported in Figure 11 and in Table 5 (column "Modified input parameters"). The performance indices of Table 5 reveal that the introduction of the modified input parameters significantly improves the ANN capability to represent the structures with bn. The representation of the data by VD reaches performance indices that are comparable to the ones of the original ANN. By comparing the corresponding charts in Figures 9 and 11, it can be observed that the scatter associated to the dataset BO is reduced, the $95 \%$ confidence bands are now comparable or even narrower than the $95 \%$ optimal bands and the overestimation bias associated to the data by VD has disappeared. The analysis of Figure 11-right indicates that the data with bn are even better represented by the modified input parameters than the data without bn, which were used in the ANN training.

In conclusion, adopting the modified input parameters $R_{c, e q} B_{e q}$ and $\gamma_{f, e q}^{\prime}$ may allow the extension of the ANN field of validity to the structures with bn. This modification could be simply introduced in the ANN tool without retraining the networks, as it does not require to include further input parameters in the ANN input set to schematize the geometry of the bn.
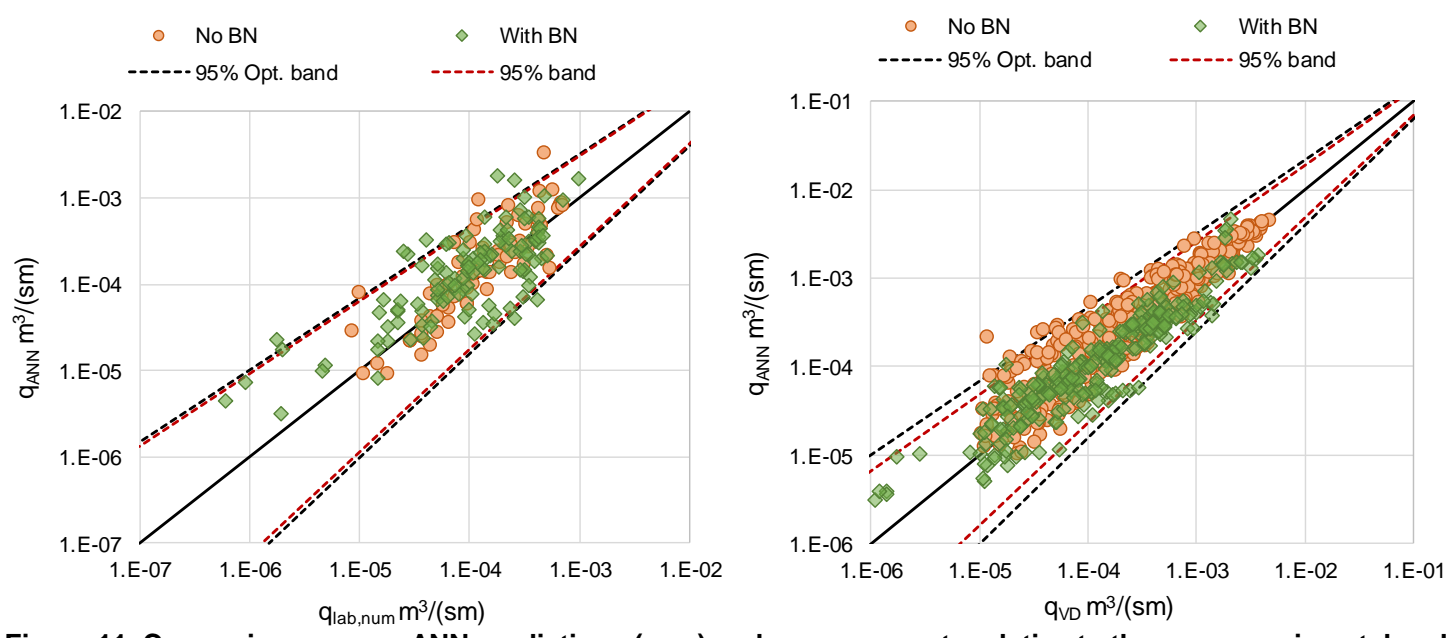

Figure 11. Comparison among ANN predictions $\left(q_{A N N}\right)$ and measurements relative to the new experimental and numerical data $\left(q_{l a b, n u m}\right.$, left panel) and to the test by VD $\left(q_{v D}\right.$, right panel). Predictions derived by the modified ANN input parameters accounting for the presence of the bullnoses. Data distinguished between structures with and without bullnoses.

\section{CONCLUSIONS}

A new database of 221 laboratory and numerical experiments on wave overtopping against dikes with berms, crown walls and bullnoses has been recently collected at the University of Bologna. The new data include a variety of geometrical cross-sections and wave attacks that partially reproduce and mostly extend the variety of the conditions already tested by Van Doorslaer et al. (2015). The two main novelties of the new experiments regard: i) the inclusion of breaking waves and ii) dikes with finite berm widths (instead of promenades) and milder slopes.

In the practice, it is found that, in the range of the tested conditions, the introduction of a bullnose can reduce $q$ of the $15-35 \%$ for the same wall height, crest height and wave attack. The effect increases with decreasing the wave discharge. The reduction achieved with $\varepsilon=30^{\circ}$ is very similar to the reductions achieved with higher bullnoses inclinations. The effect of the parameter $\lambda$ is modest.

The new data on overtopping have been compared to the existing methods for the prediction of $q$, in order to verify, update and extend the field of validity of the methods themselves. The predicting methods considered in this research are: the EurOtop (2016) formulae and ii) the EurOtop ANN (Zanuttigh et al., 2016).

The EurOtop formulae include two different reduction factors to represent the effects of the bullnose and the crown wall in case of non-breaking waves (the coefficient $\gamma^{*}$ developed by VD), and of the crown wall only in case of breaking waves (the coefficient $\gamma_{v}$ ). The main outcomes of the application of the formulae to the new data are:

- $\quad$ the correction factor $\gamma^{*}$ of the EurOtop (2016) formulae for non-breaking waves (Eq. 5.11) can be applied as it is also to the new structure configurations tested with the new experiments carried out. 
Therefore, the range of validity of the EurOtop (2016) Eq.s 5.45-5.52 can be extended as follows: $\cot \alpha_{d}=2,3,4 ; \xi_{m-1,0}=1.8-4.8 ; B / L_{m-1,0}=0.013 ; 0.5$; horizontal berm.

- To represent the effects of the bullnose in case of breaking waves, the correction factor $\gamma_{v}$ of the EurOtop (2016) Eq. 5.10, should be replaced by the correction factor $\gamma^{* *}$ developed on the basis of the new experiments and modelled on the existing $\gamma^{*}$ factor and presented in this contribution for the first time.

- the correction factor $\gamma^{* *}$ could also replace $\gamma^{*}$ in case of non-breaking waves (Eq. 5.11), as the value of $\gamma^{* *}$ converges to the value $\gamma^{*}$ of for values of $\xi_{m-1,0} \geq 2$.

The EurOtop ANN has been trained on data with crown walls without bullnoses exclusively, and therefore, at the present state, it is not able to account for the presence of the bullnose. It tends to overestimate $q$ in case of structures with bullnoses. A re-schematization of the input parameters $R_{c}, B$ and $\gamma_{f}$ is required to ensure the correct representation of bullnoses. The schematization proposed in this work does not involve neither the retraining of the ANN nor the inclusion of additional input parameters, and it is going to be included in the future in the online tool.

\section{ACKNOWLEDGMENTS}

The support of the European Commission through the Horizon 2020 project BRIGAID ("BRIdging the GAp for Innovations in Disaster resilience", www.brigaid.eu) is gratefully acknowledged.

\section{REFERENCES}

Den Heijer, F., 1998. Golfoverslag en krachten op vertical waterkeringsconstructies. Rapport H2014 (in Dutch).

EurOtop, 2007. European Manual for the Assessment of Wave Overtopping. T. Pullen, N.W.H. Allsop, T. Bruce, A. Kortenhaus, H. Schüttrumpf and J.W. van der Meer. At: www.overtopping-manual.com.

Eurotop. 2016. In: Pullen, T., Allsop, N.W.H., Bruce, T., Kortenhaus, A., Schüttrumpf, H., van der Meer, J.W. (Eds.), Wave Overtopping of Sea Defences and Related Structures - Assessment Manual. www.overtopping-manual.com.

Formentin, S.M., Zanuttigh, B., van der Meer, J.W. and Lara, J.L., 2014. Overtopping flow characteristics at emerged and over-washed dikes, Proc. of XXXIV International Conference on Coastal Engineering, Seoul (ROK). http://dx.doi.org/10.9753/icce.v34.structures.7e

Formentin S.M., Zanuttigh B. and J.W. van der Meer. 2017. A neural network for predicting wave reflection, overtopping and transmission, Coastal Engineering Journal, 59, No. 2, 1750006, 31 pp.

Formentin S.M. and Zanuttigh B., 2018. A new method to estimate the overtopping and overflow discharge at over-washed and breached dikes, Coastal Engineering, 140, pp. 240-256. https://doi.org/10.1016/j.coastaleng.2018.08.002

Formentin S.M. and Zanuttigh B., in press. A methodological approach for the development and verification of neural networks based on an application to wave-structure interaction processes, Coastal Engineering Journal, https://doi.org/10.1080/21664250.2018.1503402

Lara, J.L., Ruju, A. and Losada, I.J., 2011. Reynolds Averaged Navier-Stokes modelling of long waves induced by a transient wave group on a beach. Proceedings of the Royal Society A, vol. 467, pp.12151242.

TAW 2003. Guideline wet infrastructure. (In Dutch: Leidraad Kunstwerken). Technical Advisory Committee for Flood Defence in the Netherlands (TAW). Delft.

Van der Meer, J.W., 1997. Golfoploop en golfoverslag bij dijken. Rapport H2458 (in Dutch).

Van der Meer, J.W., Verhaeghe, H. and Steendam, G.J. 2009. The new wave overtopping database for coastal structures. Coastal Engineering 56, 108-120.

Van Doorslaer, K., De Rouck, J., Audenaert, S. and V. Duquet. 2015. Crest modifications to reduce wave overtopping of non-breaking waves over a smooth dike slope. Coastal Engineering, 101, 69-88.

Van Doorslaer, K., De Rouck, J., and J.W. van der Meer., 2016. The reduction of wave overtopping by means of a storm wall, Proc. of the 35th International Conference on Coastal Engineering, Antalya (TR), 2016.

Zanuttigh B., Formentin S.M., and J.W. van der Meer. 2016 a. Prediction of extreme and tolerable wave overtopping discharges through an advanced neural network, Ocean Engineering, 127, 7-22.

Zanuttigh B., Formentin S.M., and J.W. van der Meer. 2016 b. Update of the EurOtop neural network tool: improved prediction of wave overtopping, Proc. of the 35th International Conference on Coastal Engineering, Antalya (TR), 2016.

Zelt, J.A., Skjelbreia, J.E., 1992. Estimating incident and reflected wave field using an arbitrary number of wave gauges. In: Proc. 23rd International Conference of Coastal Engineering. I. pp. 777-789. 